\title{
ZnCuInS/ZnSe/ZnS Quantum Dot-Based Downconversion Light-Emitting Diodes and Their Thermal Effect
}

\author{
Wenyan Liu, ${ }^{1}$ Yu Zhang, ${ }^{1,2}$ Cheng Ruan, ${ }^{1}$ Dan Wang, \\ Tieqiang Zhang, ${ }^{2}$ Yi Feng, ${ }^{2}$ Wenzhu Gao, ${ }^{2}$ Jingzhi Yin, ${ }^{1}$ Yiding Wang, \\ Alexis P. Riley, ${ }^{3}$ Michael Z. Hu, ${ }^{4}$ and William W. Yu ${ }^{1,3}$ \\ ${ }^{1}$ State Key Laboratory on Integrated Optoelectronics and College of Electronic Science and Engineering, Jilin University, \\ Changchun 130012, China \\ ${ }^{2}$ State Key Laboratory of Superhard Materials and College of Physics, Jilin University, Changchun 130012, China \\ ${ }^{3}$ Department of Chemistry and Physics, Louisiana State University, Shreveport, LA 71115, USA \\ ${ }^{4}$ Oak Ridge National Laboratory, Oak Ridge, TN 37831, USA
}

Correspondence should be addressed to Yu Zhang; yuzhang@jlu.edu.cn, Michael Z. Hu; hutopia999@gmail.com, and William W. Yu; wyu6000@gmail.com

Received 25 June 2015; Revised 6 August 2015; Accepted 13 August 2015

Academic Editor: Peter Reiss

Copyright (c) 2015 Wenyan Liu et al. This is an open access article distributed under the Creative Commons Attribution License, which permits unrestricted use, distribution, and reproduction in any medium, provided the original work is properly cited.

\begin{abstract}
The quantum dot-based light-emitting diodes (QD-LEDs) were fabricated using blue GaN chips and red-, yellow-, and greenemitting ZnCuInS/ZnSe/ZnS QDs. The power efficiencies were measured as $14.0 \mathrm{~lm} / \mathrm{W}$ for red, $47.1 \mathrm{~lm} / \mathrm{W}$ for yellow, and $62.4 \mathrm{~lm} / \mathrm{W}$ for green LEDs at 2.6 V. The temperature effect of $\mathrm{ZnCuInS/ZnSe/ZnS} \mathrm{QDs} \mathrm{on} \mathrm{these} \mathrm{LEDs} \mathrm{was} \mathrm{investigated} \mathrm{using} \mathrm{CIE} \mathrm{chromaticity}$ coordinates, spectral wavelength, full width at half maximum (FWHM), and power efficiency (PE). The thermal quenching induced by the increased surface temperature of the device was confirmed to be one of the important factors to decrease power efficiencies while the CIE chromaticity coordinates changed little due to the low emission temperature coefficients of $0.022,0.050$, and $0.068 \mathrm{~nm} /{ }^{\circ} \mathrm{C}$ for red-, yellow-, and green-emitting ZnCuInS/ZnSe/ZnS QDs. These indicate that ZnCuInS/ZnSe/ZnS QDs are more suitable for downconversion LEDs compared to CdSe QDs.
\end{abstract}

\section{Introduction}

Semiconductor colloidal quantum dots (QDs) exhibit unique properties of tunable band gap, broad absorption, and high photoluminescence (PL) quantum yield (QY), making them highly attractive materials for wide applications, including photovoltaics [1, 2], light-emitting diodes (LEDs) [3-9], and bioimaging $[10,11]$. Achermann et al. reported the mechanism and viability of CdSe QDs-based color conversion white LEDs (WLEDs) [12], and CdSe or its derivative QDs have been most widely used as phosphors for LED fabrication by adopting one [13-15] or multiple types [16-19] of QD emitters, depending on the desired emission color. It has been demonstrated that the downconversion WLED devices integrated with red-emissive CdSe/ZnS [20-23], CdSe/CdS/CdZnS/ZnS [24], CdSe/ZnSe [25], or
CdS:Cu/ZnS [26] QDs show improved color rendering metrics.

However, the toxicity of $\mathrm{Cd}$ element makes its use undesirable in terms of human and environmental impacts, limiting the practical application of Cd-based LEDs. The $\mathrm{CuInS}_{2}$ based QDs have been investigated as low toxic alternatives. The emission color of CuInS 2 QDs can be tuned from visible to the near-infrared (near-IR), making them relevant for applications in lighting and displays. The band gap of $\mathrm{CuInS}_{2}$ QDs is tunable mainly through changing their particle size [27-29], composition [30], or alloying with $\mathrm{ZnS}$ [31-33]. There are many kinds of methods to enhance the PL QY of CuInS 2 QDs. Among them, the methods of doping $\mathrm{Zn}$ ion [31] or using dodecanethiol as both a sulfur source and a stabilizing ligand [28] have been applied widely. In 2011, Zhang et al. and Chung et al. published 
their results on highly luminescent ZnCuInS QDs [32, 34]. For LED applications, Song and Yang developed a WLED consisting of yellow-emitting $\mathrm{CuInS}_{2} / \mathrm{ZnS}$ QDs pumped by an InGaN blue LED [35]. They reported a high luminous efficiency of $63.4 \mathrm{~lm} / \mathrm{W}$. Chung et al. used ZnCuInS QDs and their LEDs exhibited a color rendering index (CRI) of 84.1 with a color temperature of $4256 \mathrm{~K}$ [6]. Chen et al. fabricated a WLED by combining red-emissive $\mathrm{CuInS}_{2}$ QDs with the commercial yellow-emissive YAG:Ce and greenemissive $\mathrm{Eu}^{2+}$ doped silicate phosphors [36]. Their warm WLED had a CRI of 92 with luminous efficiency of 45 $60 \mathrm{~lm} / \mathrm{W}$ and color temperature of $4000 \mathrm{~K}$.

In this work, we adopted colloidal $\mathrm{ZnCuInS/ZnSe/ZnS}$ QDs as the environmentally benign and nontoxic phosphor. Red-, yellow-, and green-emitting ZnCuInS/ZnSe/ZnS QDs were synthesized and deposited on GaN blue LED chips. The temperature-dependent PL spectra of QDs showed the corresponding changes of band gap, intensity, and FWHM (full width at half maximum) $[37,38]$. Therefore, the thermal effect was investigated according to the evolutions of power efficiencies (PE), FWHM, and peak wavelength.

\section{Experimental Section}

2.1. Chemicals. Indium (III) acetate (In(Ac) $\left.)_{3}, 99.99 \%\right)$, selenium powder (Se, 100 mesh), copper (I) acetate (99.99\%), zinc acetate $\left(\mathrm{Zn}(\mathrm{Ac})_{2}, 99.99 \%\right)$, oleic acid (OA, 90\%), and 1-octadecene (ODE, 90\%) were purchased from Alfa Aesar. Oleylamine (97\%), sulfur powder (S, 99.99\%), dodecylthiol (99.9\%), acetone, methanol, hexane, and toluene were purchased from Sigma-Aldrich. Tributylphosphine (TBP, 95\%) and diethyldithiocarbamic acid zinc (DECZn, 98\%) were obtained from Aladdin. All chemicals were used directly without further treatment.

2.2. Synthesis. Several solutions were prepared before the QD synthesis. $0.181 \mathrm{~g} \mathrm{DECZn} \mathrm{was} \mathrm{mixed} \mathrm{with} 6 \mathrm{~mL}$ TBP and $24 \mathrm{~mL}$ ODE under $\mathrm{N}_{2}$ and was heated to $70^{\circ} \mathrm{C}$ for $30 \mathrm{~min}$ until a colorless solution was obtained as DECZn/TBP/ODE solution. $0.078 \mathrm{~g}$ Se powder was dissolved into $10 \mathrm{~mL}$ TBP at room temperature as Se/TBP solution. $0.1003 \mathrm{~g} \mathrm{ZnO}$ and $2.073 \mathrm{~g} \mathrm{OA}$ were mixed with $10 \mathrm{~mL} \mathrm{ODE}$ and loaded into a $25 \mathrm{~mL}$ three-necked flask; the mixture was degassed under $\mathrm{N}_{2}$ for $10 \mathrm{~min}$ and was heated to $200^{\circ} \mathrm{C}$ until a colorless solution was formed as $\mathrm{Zn}$ solution.

ZnCuInS core QDs were synthesized following the method by Zhang et al. [32] In a typical synthesis of ZnCuInS core QDs, $0.0528 \mathrm{~g}$ zinc acetate $(0.3 \mathrm{mmol}), 0.0292 \mathrm{~g}$ indium acetate $(0.1 \mathrm{mmol}), 0.0190 \mathrm{~g}$ copper (I) acetate $(0.1 \mathrm{mmol})$, 1-dodecanethiol $(2 \mathrm{mmol})$, and oleic acid $(0.6 \mathrm{mmol})$ were mixed with $4 \mathrm{~mL}$ ODE in a three-neck flask and degassed under $\mathrm{N}_{2}$ for $10 \mathrm{~min}$. The mixture was heated to $210^{\circ} \mathrm{C}$ until the powders dissolved completely. The sulfur solution $(0.3 \mathrm{mmol} \mathrm{S}$ dissolved in $0.5 \mathrm{~mL}$ oleylamine) was quickly injected into the solution. After maintaining the temperatures (210, 180, and $150^{\circ} \mathrm{C}$ for red, yellow, and green QDs, resp.) for $10 \mathrm{~min}$, the mixture was heated to $230^{\circ} \mathrm{C}$ and maintained for
5 min and then cooled to room temperature. The core QDs were thus achieved.

Then, $\mathrm{ZnSe} / \mathrm{ZnS}$ shell/shell were synthesized as follows: $2 \mathrm{~mL}$ Se/TBP and $2 \mathrm{~mL} \mathrm{ZnO} / \mathrm{OA} / \mathrm{ODE}$ solution were added drop by drop into the above solution. After $10 \mathrm{~min}$, another $2 \mathrm{~mL} \mathrm{Se} / \mathrm{TBP}$ and $2 \mathrm{~mL} \mathrm{ZnO} / \mathrm{OA} / \mathrm{ODE}$ solution were added dropwise. $10 \mathrm{~min}$ later, $3 \mathrm{~mL}$ DECZn/TBP/ODE was added into the solution. Then, the temperature was maintained at $150^{\circ} \mathrm{C}$ for 2 hours. The solution was mixed with an equal volume of hexane and twice the volume of methanol to extract byproducts. After that, the QDs were redispersed in hexane and were precipitated by twice the volume of methanol and an equal volume of acetone to get pure ZnCuInS/ZnSe/ZnS QD powders [39-41].

2.3. Downconversion LEDs. ZnCuInS/ZnSe/ZnS QDs were dispersed into chloroform. A transparent epoxy was prepared by mixing EP-3400 A and EP-3400 B (Swancor Fine Chemical Co.) with a mass ratio of $1: 1$. Then, the QD solution was dropwise added into the epoxy. The mixture was well stirred until it became homogeneous. The QD/epoxy mixture was firstly heated at $40^{\circ} \mathrm{C}$ for $30 \mathrm{~min}$ in a vacuum chamber $(2 \times$ $10^{3} \mathrm{~Pa}$ ) to remove chloroform and bubbles in the mixture. The temperature was further gradually increased to $80^{\circ} \mathrm{C}$ and was kept at $80^{\circ} \mathrm{C}$ for $60 \mathrm{~min}$. After that, the QD/epoxy liquid mixture was deposited on LED chips dropwise and then was heated at $120^{\circ} \mathrm{C}$ for $45 \mathrm{~min}$ in the vacuum chamber to solidify the QD/epoxy on the LED chips.

2.4. Characterization. Absorption spectra were measured on a Perkin-Elmer Lambda $950 \mathrm{UV}$-vis spectrophotometer. Photoluminescence (PL) spectra were recorded on a PerkinElmer LS50B spectrophotometer. For temperature control measurements, the sample stage was placed on a heating plate which controlled the temperature of the sample in the process of measurement. The sample was heated at an aimed temperature for $20 \mathrm{~min}$ before measurements. Temperature of $\mathrm{GaN}$ chip was measured by an infrared (IR) thermal image camera (FLIR T250). Images of LEDs were recorded with a Canon EOS 600D camera. The electrical characterization of the devices was performed on a Keithley 2612B source meter. The PL QYs of the QDs were calculated by comparing their integrated emissions with that of rhodamine $6 \mathrm{G}$ dissolved in ethanol (QY of $\sim 96 \%$ was adopted) at an identical optical density of $\sim 0.05$ with $450 \mathrm{~nm}$ excitation. Samples for TEM studies were prepared by placing a $4 \mu \mathrm{L}$ toluene solution of QDs on ultrathin carbon-film-coated copper grids in glove box. The element molar ratio of QD cores was determined with a Thermo Fisher Scientific X Series 2 inductively coupled plasma-mass spectrometer (ICP-MS). Prior to the analysis, the sample was dissolved in a mixed solution of ultrapure nitric acid and ultrapure hydrochloric acid. And then the solution was diluted by deionized water.

\section{Results and Discussion}

The UV-vis absorption and PL spectra of the QDs in chloroform are given in Figure 1(a). The PL peak wavelengths of 


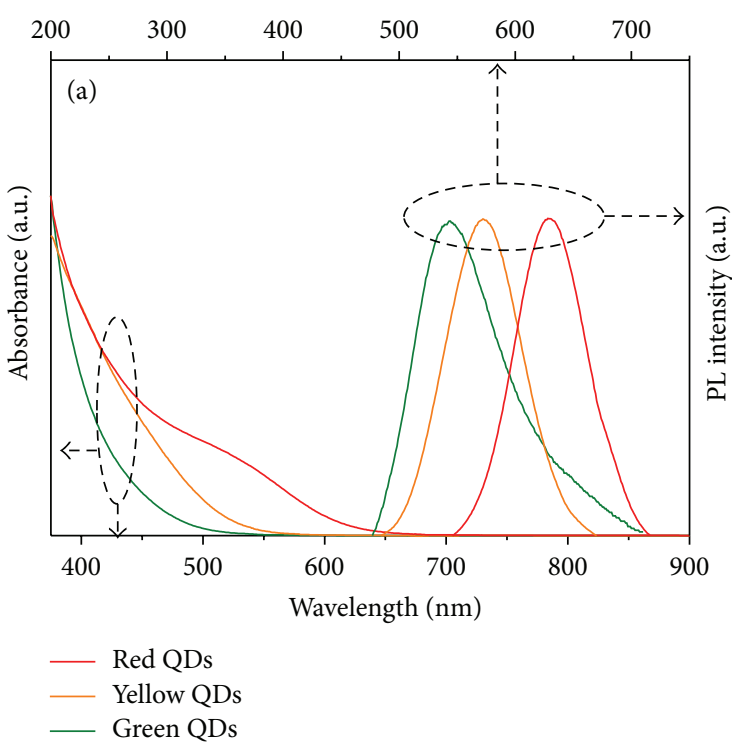

(b)
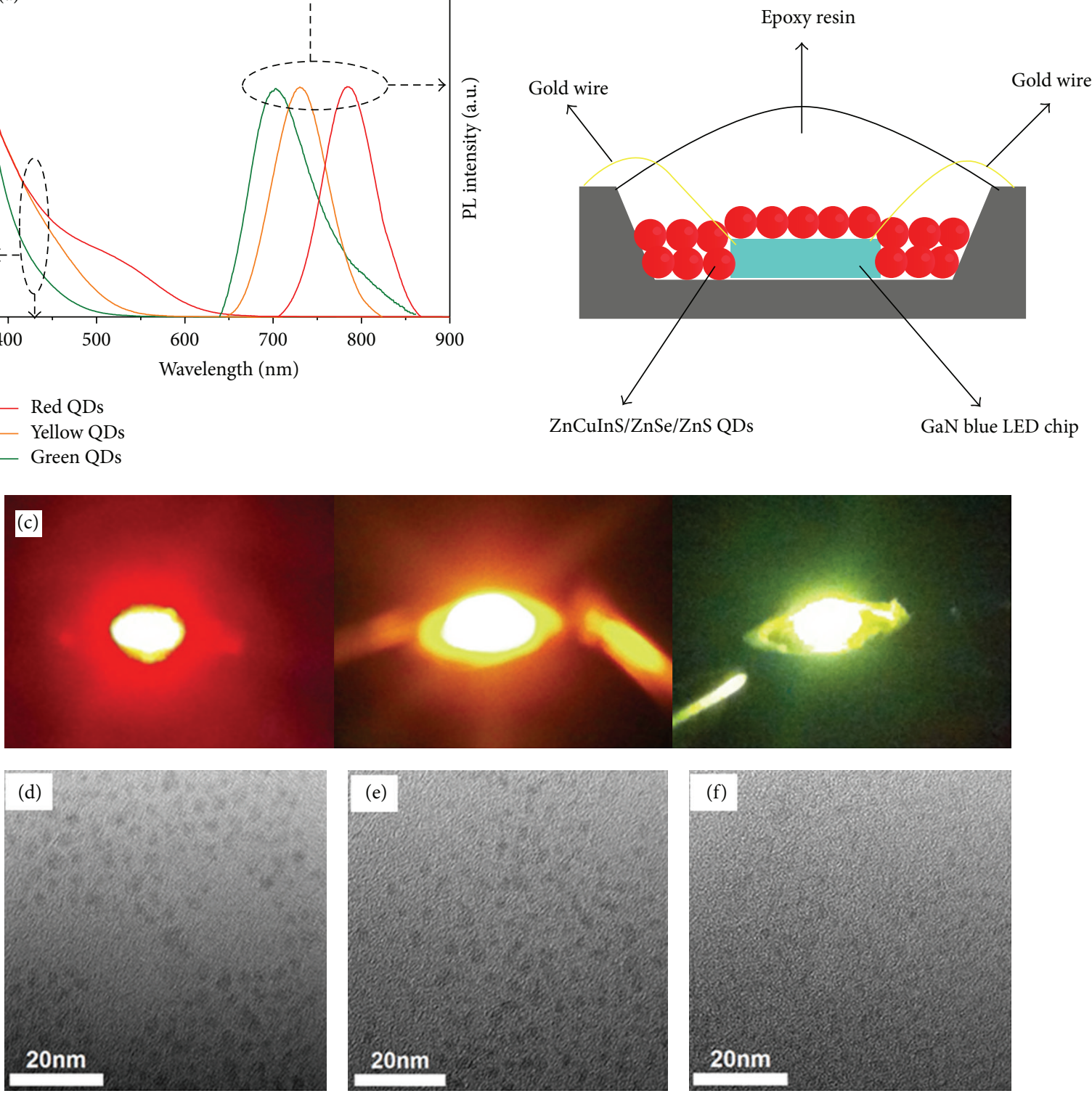

Figure 1: The absorption and PL spectra of ZnCuInS/ZnSe/ZnS QDs in chloroform (a); the device structure (b) and the emitting color photograph (c) of QD-LEDs; the TEM images of red (d), yellow (e), and green (f) ZnCuInS/ZnSe/ZnS QDs.

three ZnCuInS/ZnSe/ZnS QDs were $629.3 \mathrm{~nm}$ (PL QY 60\%) for red, $572.7 \mathrm{~nm}$ (PL QY 59\%) for yellow, and $543.5 \mathrm{~nm}$ (PL QY 65\%) for green QDs, respectively. As shown in Figures $1(\mathrm{~d})-1(\mathrm{f})$, the average sizes of three $\mathrm{ZnCuInS} / \mathrm{ZnSe} / \mathrm{ZnS}$ QDs were $3.4 \mathrm{~nm}$ for red, $2.8 \mathrm{~nm}$ for yellow, and $2.0 \mathrm{~nm}$ for green QDs, respectively. The elemental ratios of the red-, yellow-, and green-emitting $\mathrm{ZnCuInS}$ cores were $\mathrm{Zn}: \mathrm{Cu}: \mathrm{In}: \mathrm{S}=$ $\sim 3.0: 1.0: 1.3: 9.3, \sim 3.1: 1.0: 1.4: 9.2$, and $\sim 3.0: 1.0: 1.4: 9.4$, respectively, by ICP-MS. The elemental ratios are almost the same for three $\mathrm{ZnCuInS} / \mathrm{ZnSe} / \mathrm{ZnS}$ QDs. Therefore, the blue shifts of UV-vis absorption and PL spectra are attributed to the decreasing size. The QD-LEDs consisted of a GaN blue LED (HXGD-DZ-3w) and the QDs, as shown in Figure 1(b). In this device configuration, the $452.0 \mathrm{~nm}$ blue light from the GaN LED acted as the host, which could effectively excite the $\mathrm{ZnCuInS} / \mathrm{ZnSe} / \mathrm{ZnS}$ QDs. The QD phosphors converted the blue light into red, yellow, and green light. Photographs of red, yellow, and green emitting $\mathrm{ZnCuInS/ZnSe/ZnS} \mathrm{QD-}$ LEDs operated at a bias of $2.6 \mathrm{~V}$ are shown in Figure $1(\mathrm{c})$.

Figure 2(a) shows the luminescence of red QD-LED at 2.6 V with different quantity (showing the added QD/epoxy liquid mixture volume) of $\mathrm{ZnCuInS} / \mathrm{ZnSe} / \mathrm{ZnS}$ QDs. Two emission bands of blue and red were contributed by $\mathrm{GaN}$ chip and ZnCuInS/ZnSe/ZnS QDs, respectively. The blue emission intensity of the underlying GaN LED chip decreased while the PL intensity of the QDs increased with the increasing amount of $\mathrm{ZnCuInS} / \mathrm{ZnSe} / \mathrm{ZnS}$ QDs. The blue emission disappeared when the QD layer was thick enough 


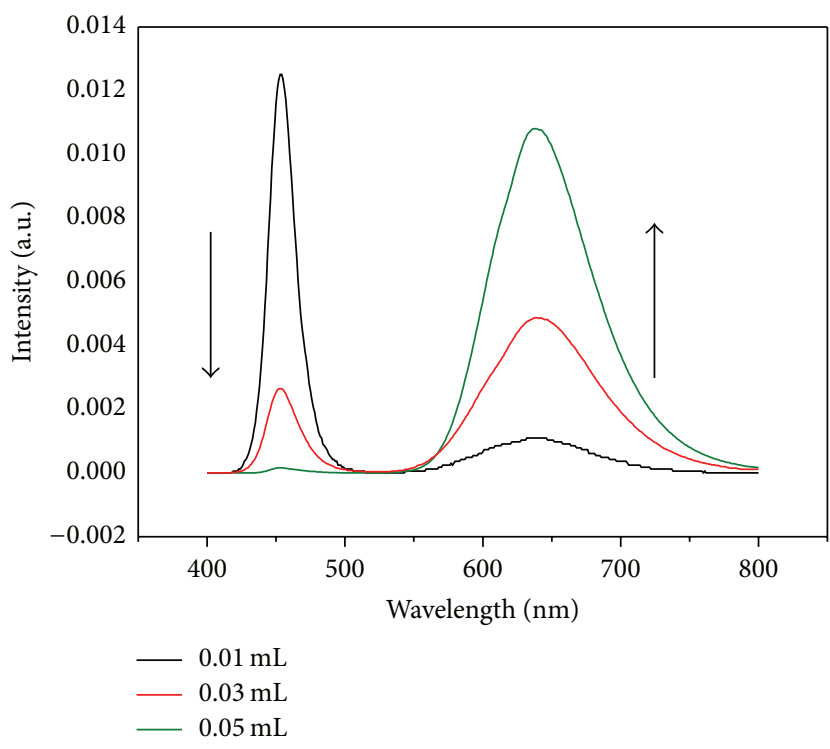

(a)

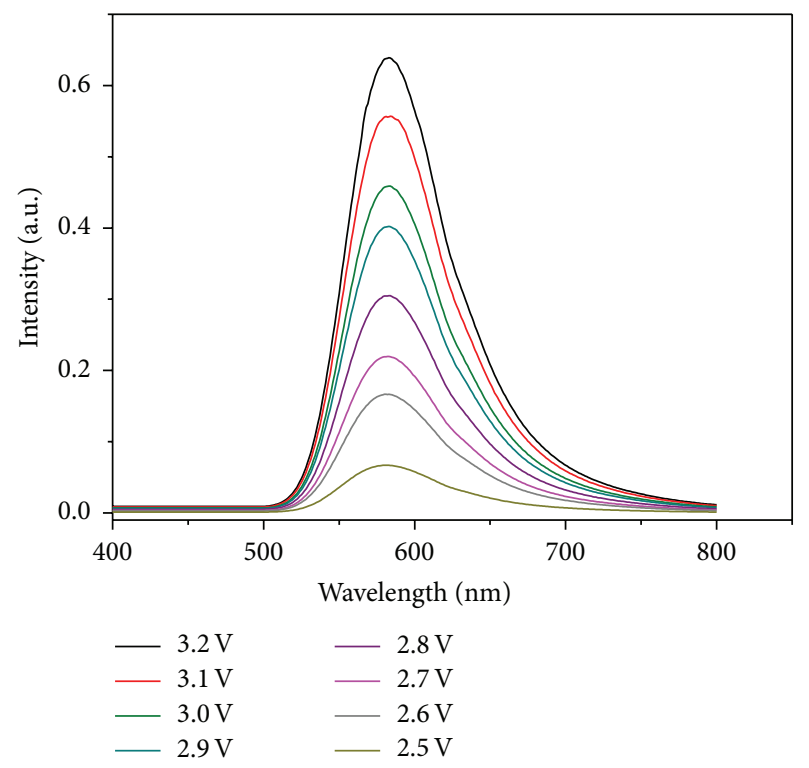

(c)

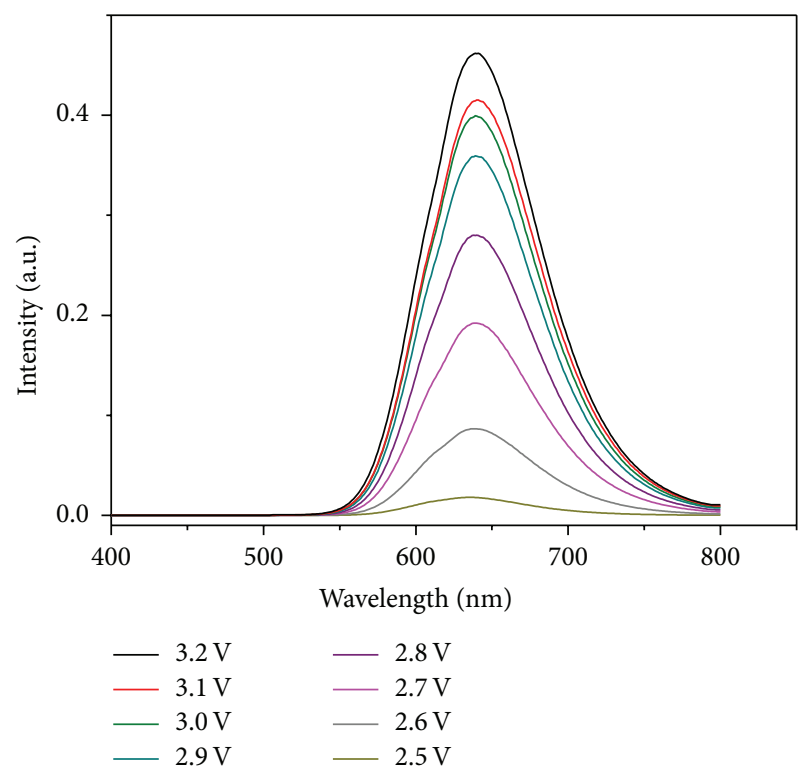

(b)

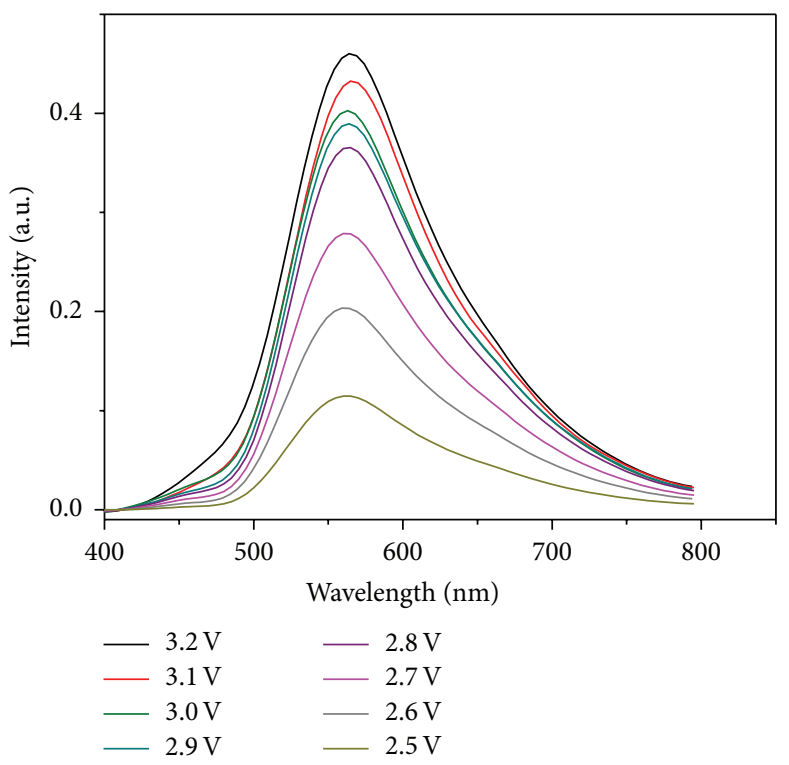

(d)

FIgURE 2: The evolution of LED spectra with the increase of QD quantity (a); the emission spectra of the as-fabricated LEDs under different voltage ((b) for red, (c) for yellow, and (d) for green LEDs).

to absorb the emission of GaN chip completely. Finally, the PL spectra of the as-fabricated three-color QD-LEDs under different voltages are shown in Figures 2(b), 2(c), and 2(d), in which the emission peaks of QDs are located at $639.3 \mathrm{~nm}$, $581.4 \mathrm{~nm}$, and $562.0 \mathrm{~nm}$, respectively. The emission of the QD-LEDs had some red-shift compared to that of the original solution, which may be caused by the agglomeration of the QDs [20, 42-44].

The Commission Internationale de l'Eclairage (CIE) coordinates of the LED were calculated through the data of emission spectra; they were $(0.660,0.339),(0.655,0.344)$ for red-, $(0.521,0.475),(0.524,0.462)$ for yellow-, and $(0.449$, $0.519),(0.437,0.502)$ for green-emitting QD-LEDs at $2.5 \mathrm{~V}$ and $3.2 \mathrm{~V}$, respectively, as shown in Figure 3(a), indicating a good color stability. FWHM and the peak position for QD-LEDs under different voltage are shown in Figures 3(b), 3(c), and 3(d). Due to the defect-related emission of $\mathrm{ZnCuInS} / \mathrm{ZnSe} / \mathrm{ZnS}$ QDs, the red-shift and broaden of emission spectra with increasing voltage were little as shown in Figure 3.

FWHM of these LED emissions broadened from 84.7 to $90.3 \mathrm{~nm}$ for red, from 77.2 to $79.6 \mathrm{~nm}$ for yellow, and from 


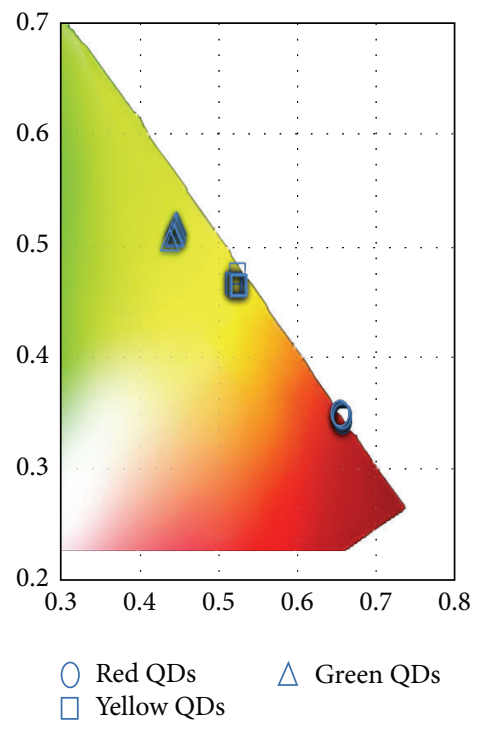

(a)

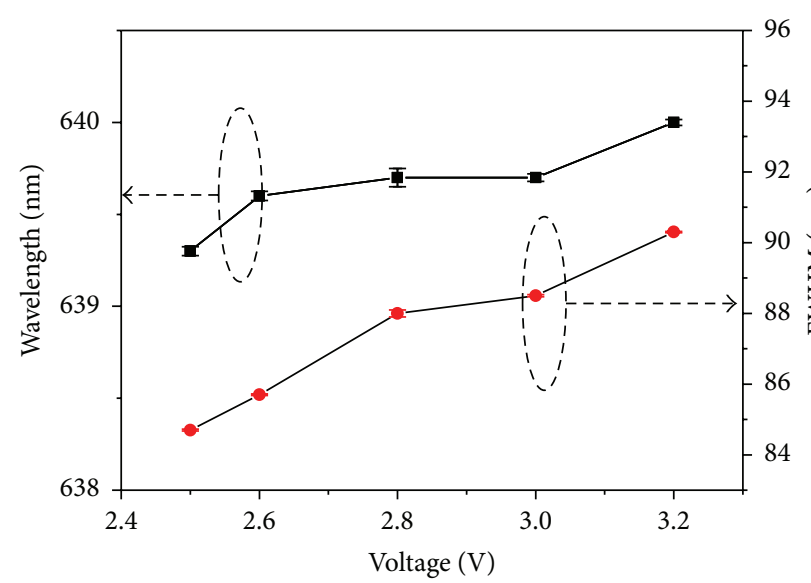

(b)

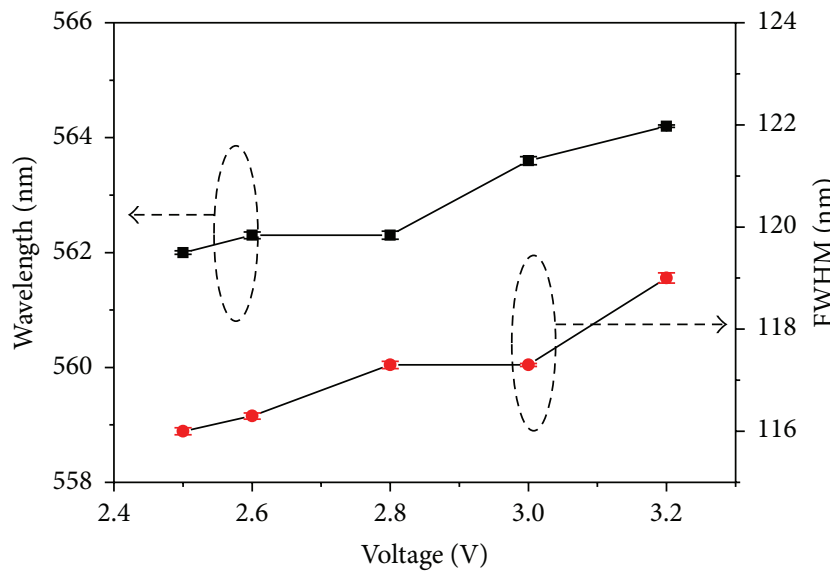

(d)

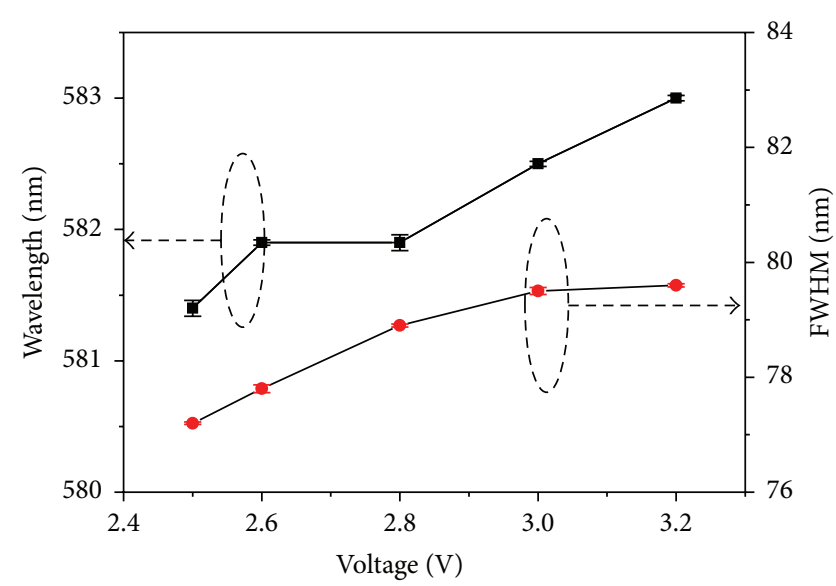

(c)

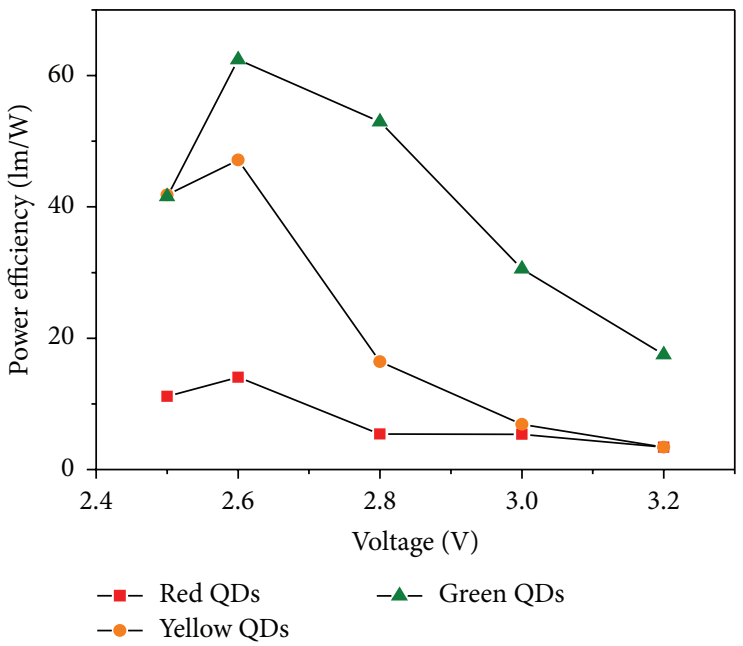

(e)

FIGURE 3: The CIE coordinates of LEDs under different voltage (a); FWHM and the peak position of LEDs under different voltage ((b) for red, (c) for yellow, and (d) for green LEDs); and power efficiency (PE) of LEDs at different voltage (e). 
116 to $119 \mathrm{~nm}$ for green LEDs, respectively, with increased voltage. The spectra peaks of red-, yellow-, and greenemitting QD-LEDs at 2.5 V were 639.3, 581.4, and $562.0 \mathrm{~nm}$, respectively, and showed slight red-shift with the increasing voltage. When the voltage increased from $2.6 \mathrm{~V}$ to $3.2 \mathrm{~V}$, the PL spectra shifted to red from 639.6 to $640 \mathrm{~nm}$ for redemitting QD-LEDs, from 581.9 to $583 \mathrm{~nm}$ for yellow-emitting QD-LEDs, and from 562.3 to $564.2 \mathrm{~nm}$ for green-emitting QD-LEDs. The peak position changed by only $0.7 \mathrm{~nm}, 1.6 \mathrm{~nm}$, and $2.2 \mathrm{~nm}$ for red-, yellow-, and green-emitting QD-LEDs, respectively.

The power efficiencies (PE) of the as-fabricated QD-LEDs were calculated on based the following equation [45]:

$$
\eta=\frac{F}{(I V)}=\frac{\pi S L}{(I V)}=\frac{\pi L}{(J V)},
$$

where $\eta$ is the power efficiencies $(\mathrm{PE}, \mathrm{lm} / \mathrm{W}), S$ is the lightemitting area, $F$ is the luminous flux $(\mathrm{lm}), I$ is the current (A), $V$ is the voltage (V), $\pi$ is the ratio of circumference to diameter $(\mathrm{Pi}), L$ is the luminance of $\operatorname{LED}\left(\mathrm{cd} / \mathrm{m}^{2}\right)$, and $J$ is the current density $\left(\mathrm{A} / \mathrm{m}^{2}\right)$. The PE increased with the increase of bias from $2.5 \mathrm{~V}$ to $2.6 \mathrm{~V}$, corresponding to the maximum values of $14.0 \mathrm{~lm} / \mathrm{W}, 47.1 \mathrm{~lm} / \mathrm{W}$, and $62.4 \mathrm{~lm} / \mathrm{W}$ for red, yellow, and green LED at $2.6 \mathrm{~V}$. In terms of the PE, the values are compatible with those of CdSe-based QD-LEDs [46].

The PE decreased when the bias further increased, which was caused by two factors: the PL QY of $\mathrm{ZnCuInS/ZnSe/ZnS}$ QDs and the GaN LED efficiency droop at high voltage. The drop of GaN or InGaN LED efficiency has been reported due to the effects induced by Auger recombination, densityactivated defect recombination, and carrier leakage [47-49]. In order to deconvolute the voltage and thermal effects on device output, the emission spectra of QD films on the glass excited by GaN LEDs were record with increasing bias from $2.5 \mathrm{~V}$ to $3.2 \mathrm{~V}$ as shown in Figure $4(\mathrm{a})$. As a result, the emission peak and FWHM of QD films were not affected by the increasing bias. Then, the thermal effect of the devices was investigated. The images of the temperature profiles of the surface of GaN chip were measured by a thermal infrared imager (Figures $4(\mathrm{~b})-4(\mathrm{~d})$ ). The working temperature of device changed from 28.1 to $60.3^{\circ} \mathrm{C}$ with the bias increased from 2.5 to $3.2 \mathrm{~V}$ as shown in Figure 4(e). As we know, the heat is proportional to the square of the voltage. Therefore, the temperature increased slowly when the voltage was low but increased quickly when the voltage was high. As shown in Figure 4(e), the temperature increased with the increasing voltage. At low voltages, the change of PL QY of ZnCuInS/ZnSe/ZnS QDs was inconspicuous. But the PL QY decreased sharply at high voltages. This is because the PL spectra were temperature-dependent [37]. Therefore, the intensity of the emission spectra of QD-LEDs increased more at low voltages than that at high voltages. Correspondingly, the $\mathrm{PE}$ of QD-LEDs decreased with the increasing voltage when the voltage was higher than $2.6 \mathrm{~V}$.

The temperature-dependent PL spectra of the ZnCuInS/ ZnSe/ZnS QD films were collected by an optical fiber (the QD films were placed on a heating plate). The relative temperature-dependent peak intensity of $\mathrm{ZnCuInS} / \mathrm{ZnSe} /$
ZnS QDs decreased to $69.6 \%$ at $40^{\circ} \mathrm{C}$ and to $41.6 \%$ at $60^{\circ} \mathrm{C}$ compared with the one at room temperature (Figure $4(\mathrm{f})$ ). In order to understand the temperature-dependent PL and determine the activation energy for thermal quenching, the Arrhenius equation was employed to fit the thermal quenching data [50]:

$$
I_{(T)}=\frac{I_{0}}{1+c \exp (-E / k T)},
$$

where $I_{0}$ is the initial intensity, $I_{(T)}$ is the intensity at temperature $T, c$ is a constant, $E$ is the activation energy for thermal quenching, and $k$ is the Boltzmann constant. The fitting curve is shown in the inset of Figure 4(f). As shown in Figure 4(e), the surface temperature of the GaN chip increased slowly at low voltages, but sharply at high voltages. Correspondingly, the PL QY of ZnCuInS/ZnSe/ZnS QDs was little affected at low voltages than that at high voltages. It is because the activation energy of $\mathrm{ZnCuInS/ZnSe/ZnS} \mathrm{QDs} \mathrm{was} \mathrm{enough}$ to restrain the thermal motion. When the voltage increased from $2.5 \mathrm{~V}$ to $3.2 \mathrm{~V}$, the energy of thermal motion of $(3 / 2) k T$ increased from $25.9 \mathrm{meV}$ to $43 \mathrm{meV}$. The energy of $43 \mathrm{meV}$ was close to the activation energy of $50 \mathrm{meV}$. Therefore, the activation energy was not enough to restrain the effect of thermal motion. As shown in Figure 2, the intensity of the emission spectra of QD-LEDs increased more at low voltages than that at high voltages. Therefore, the suitable activation energy for the material of downconversion was concerned with the voltage of working range of the LEDs. The activation energy of $50 \mathrm{meV}$ was not enough to overcome the thermal effect. But the activation energy was higher than those of CdSe and CdTe QDs [51, 52], which makes a relatively higher thermal stability of these ZnCuInS/ZnSe/ZnS QDs [53-55].

Emission temperature coefficient, the peak shift divided by the temperature change, is used to quantify the thermal effect on PL peak positions. A red-shift of $5.5 \mathrm{~nm}$ (green emission) was observed in the PL spectra of $\mathrm{ZnCuInS} / \mathrm{ZnSe} / \mathrm{ZnS}$ QDs when the temperature increased from 20 to $100^{\circ} \mathrm{C}$, corresponding to a temperature coefficient of $0.068 \mathrm{~nm} /{ }^{\circ} \mathrm{C}$ as shown in Figure 4(f). The spectra peak of the green-emitting LEDs showed a red-shift of $2.2 \mathrm{~nm}$ when the voltage increased from $2.5 \mathrm{~V}$ to $3.2 \mathrm{~V}$ with the corresponding increasing temperature of $32.2^{\circ} \mathrm{C}$, which was in good accordance with the temperature coefficient of $\mathrm{ZnCuInS/ZnSe/ZnS} \mathrm{QDs.}$

Compared to CdSe QDs, the temperature-dependent shift of the PL spectra of $\mathrm{ZnCuInS/ZnSe/ZnS} \mathrm{QDs} \mathrm{is} \mathrm{small.}$ The temperature coefficients of $0.022 \mathrm{~nm} /{ }^{\circ} \mathrm{C}$ and $0.050 \mathrm{~nm} /{ }^{\circ} \mathrm{C}$ were found for red- and yellow-emitting LEDs, respectively; all were much lower than that of CdSe QDs $\left(\sim 0.1 \mathrm{~nm} /{ }^{\circ} \mathrm{C}\right)$ $[56,57]$. The low temperature coefficients might be attributed to the donor or acceptor-related recombination because the surface-related recombination, conduction to defect state recombination, and donor-acceptor pair (DAP) recombination were considered to coexist in $\mathrm{ZnCuInS/ZnSe/ZnS} \mathrm{QDs}$ $[37,57,58]$. The PE values of the $\mathrm{ZnCuInS} / \mathrm{ZnSe} / \mathrm{ZnS}$ QDLEDs are approximate to the CdSe QD-LEDs. For the toxicity, the $\mathrm{ZnCuInS} / \mathrm{ZnSe} / \mathrm{ZnS}$ QDs do not contain toxic Cd element. But for the color purity, the CdSe QD-LEDs are better than $\mathrm{ZnCuInS/ZnSe/ZnS} \mathrm{QD-LEDs,} \mathrm{because} \mathrm{their} \mathrm{emissions}$ 


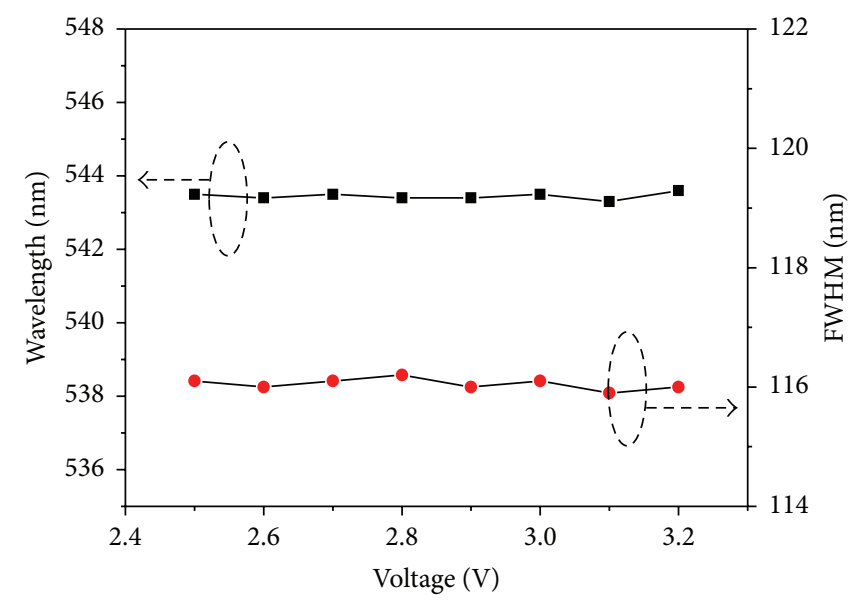

(a)

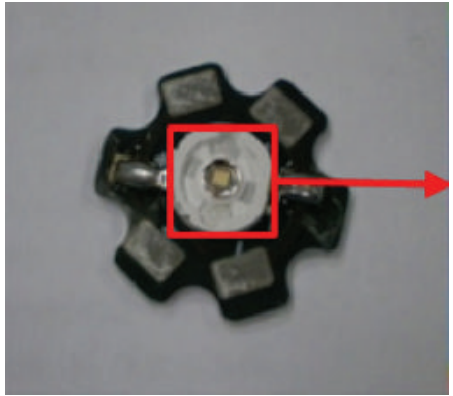

(b)

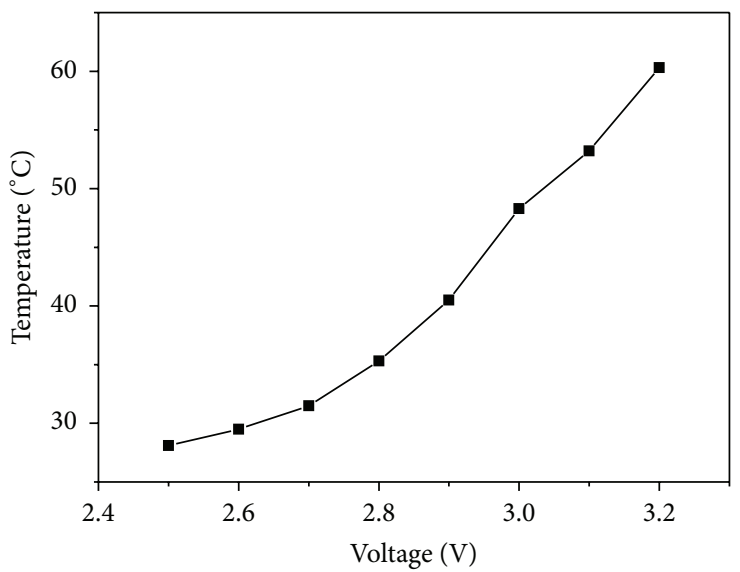

(e)

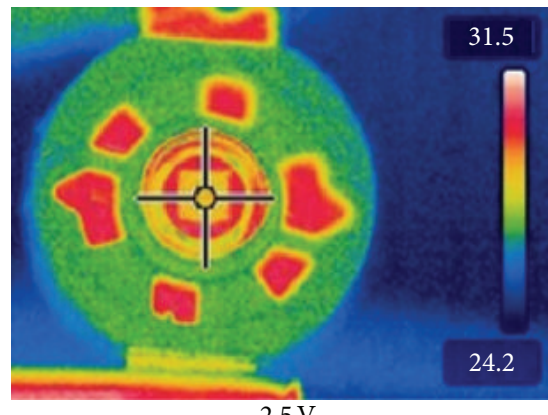

(c)

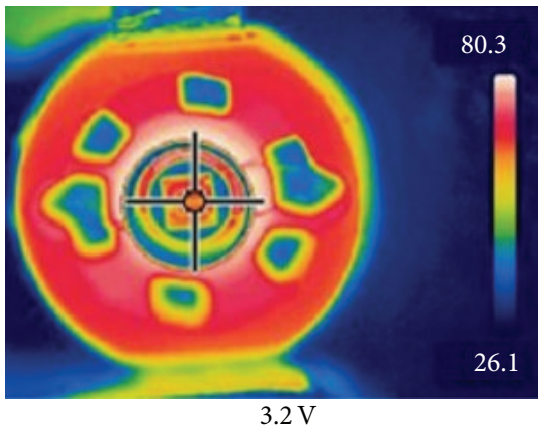

(d)

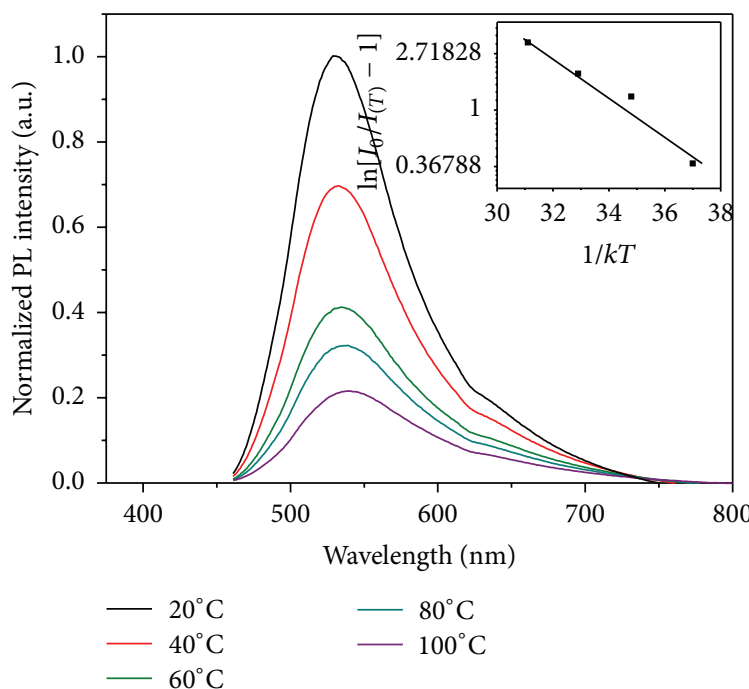

(f)

FIGURE 4: The peak position and FWHM of PL spectra of QD film excited by LED with different working bias (a); the images of GaN LED (b) and the thermal distribution of GaN LED at operating voltages of 2.5 and $3.2 \mathrm{~V}$ (c and d); the temperature of GaN chip at different voltages (e); temperature-dependent PL spectra (f) of green QDs in the range from 20 to $100^{\circ} \mathrm{C}$ (inset: the fitting curve according to (2)). 
are narrower. This is still an active research topic in this group and many other labs. The color stability is an important specification for the monochromatic QD-LEDs and we found the temperature coefficients of $\mathrm{ZnCuInS} / \mathrm{ZnSe} / \mathrm{ZnS}$ QDs were small. Putting things together, $\mathrm{ZnCuInS/ZnSe/ZnS} \mathrm{QDs}$ are more suitable for fabricating the QD-LEDs than CdSe QDs.

\section{Conclusions}

QD-based downconversion LEDs were fabricated using blue GaN chip and red-, yellow-, and green-emitting ZnCuInS/ $\mathrm{ZnSe} / \mathrm{ZnS}$ QDs. The CIE chromaticity coordinates were $(0.658,0.341) /(0.655,0.344)$ for red, $(0.517,0.465) /(0.524$, $0.462)$ for yellow, and $(0.446,0.518) /(0.437,0.502)$ for green LEDs at 2.6/3.2 V with PE of 14.0/3.4, 47.1/3.4, and $62.4 / 17.5 \mathrm{~lm} / \mathrm{W}$, respectively. The thermal effect was investigated and small red-shift as well as a broadening of the emission peak was observed with increased temperature. The CIE chromaticity coordinates changed very little due to the low temperature coefficients of $\mathrm{ZnCuInS/ZnSe/ZnS} \mathrm{QDs}$ which meant they were more suitable for downconversion LEDs compared to CdSe QDs. However, the decreasing PE caused by the increasing temperature of the GaN chip was still vital for the performance of QD-LEDs. Therefore, it is necessary to avoid higher working temperature of the GaN chips.

\section{Conflict of Interests}

All authors declare that this paper does not have any content with conflict of interests.

\section{Acknowledgments}

This work was financially supported by the National Natural Science Foundation of China (61106039, 51272084, 61306078, 61225018, and 61475062), the National Postdoctoral Foundation (2011049015), the Jilin Province Key Fund (20140204079GX), the State Key Laboratory on Integrated Optoelectronics (IOSKL2012ZZ12), and NSF (1338346). While this paper was being prepared, part of Dr. Hu's time was sponsored by the US Department of Energy BETO Program, ARPAE Program, and LDRD/SEED Program at the Oak Ridge National Laboratory.

\section{References}

[1] H. Zhong, Y. Zhou, Y. Yang, C. Yang, and Y. Li, "Synthesis of type II CdTe-CdSe nanocrystal heterostructured multiple-branched rods and their photovoltaic applications," Journal of Physical Chemistry C, vol. 111, no. 17, pp. 6538-6543, 2007.

[2] Q. Guo, S. J. Kim, M. Kar et al., "Development of $\mathrm{CuInSe}_{2}$ nanocrystal and nanoring inks for low-cost solar cells," Nano Letters, vol. 8, no. 9, pp. 2982-2987, 2008.

[3] N. Gaponik, S. G. Hickey, D. Dorfs, A. L. Rogach, and A. Eychmüller, "Progress in the light emission of colloidal semiconductor nanocrystals," Small, vol. 6, no. 13, pp. 1364-1378, 2010.
[4] V. L. Colvin, M. C. Schlamp, and A. P. Alivisatos, "Lightemitting diodes made from cadmium selenide nanocrystals and a semiconducting polymer," Nature, vol. 370, no. 6488, pp. 354357,1994

[5] Y. Zhang, C. Xie, H. Su et al., "Employing heavy metalfree colloidal quantum dots in solution-processed white lightemitting diodes," Nano Letters, vol. 11, no. 2, pp. 329-332, 2011.

[6] W. Chung, H. Jung, C. H. Lee, and S. H. Kim, "Fabrication of high color rendering index white LED using Cd-free wavelength tunable $\mathrm{Zn}$ doped $\mathrm{CuInS}_{2}$ nanocrystals," Optics Express, vol. 20, no. 22, pp. 25071-25076, 2012.

[7] H.-S. Chen, D.-M. Yeh, C.-F. Lu et al., "White light generation with CdSe-ZnS nanocrystals coated on an InGaNGaN quantum-well blue/Green two-wavelength light-emitting diode," IEEE Photonics Technology Letters, vol. 18, no. 13, pp. 1430-1432, 2006.

[8] Q. Dai, C. E. Duty, and M.Z. Hu, "Semiconductor-nanocrystalsbased white light-emitting diodes," Small, vol. 6, no. 15, pp. 1577$1588,2010$.

[9] C. Sun, Y. Zhang, Y. Wang et al., "High color rendering index white light emitting diodes fabricated from a combination of carbon dots and zinc copper indium sulfide quantum dots," Applied Physics Letters, vol. 104, no. 26, Article ID 261106, 2014.

[10] W. C. W. Chan and S. Nie, "Quantum dot bioconjugates for ultrasensitive nonisotopic detection," Science, vol. 281, no. 5385, pp. 2016-2018, 1998.

[11] W. W. Yu, "Semiconductor quantum dots: synthesis and watersolubilization for biomedical applications," Expert Opinion on Biological Therapy, vol. 8, no. 10, pp. 1571-1581, 2008.

[12] M. Achermann, M. A. Petruska, S. Kos, D. L. Smith, D. D. Koleske, and V. I. Klimov, "Energy-transfer pumping of semiconductor nanocrystals using an epitaxial quantum well," Nature, vol. 429, no. 6992, pp. 642-646, 2004.

[13] H. Song and S. Lee, "Red light emitting solid state hybrid quantum dot-near-UV GaN LED devices," Nanotechnology, vol. 18, no. 25, Article ID 255202, 2007.

[14] Y. Chen, C. Huang, Y. Su, W. Li, C. H. Yeh, and Y. Lin, "The hybridization of CdSe/ZnS quantum dot on InGaN lightemitting diodes for color conversion," IEEE Transactions on Nanotechnology, vol. 7, no. 4, pp. 503-507, 2008.

[15] C. Huang, Y. Su, Y. Chen, P. Tsai, C. Wan, and W. Li, "Hybrid CdSe-ZnS quantum Dot-InGaN-GaN quantum well red lightemitting diodes," IEEE Electron Device Letters, vol. 29, no. 7, pp. 711-713, 2008.

[16] H. Wang, K.-S. Lee, J.-H. Ryu, C.-H. Hong, and Y.-H. Cho, "White light emitting diodes realized by using an active packaging method with $\mathrm{CdSe} / \mathrm{ZnS}$ quantum dots dispersed in photosensitive epoxy resins," Nanotechnology, vol. 19, no. 14, Article ID 145202, 2008.

[17] S. Nizamoglu, T. Ozel, E. Sari, and H. V. Demir, "White light generation using $\mathrm{CdSe} / \mathrm{ZnS}$ core-shell nanocrystals hybridized with InGaN/GaN light emitting diodes," Nanotechnology, vol. 18, no. 6, Article ID 065709, 2007.

[18] H. S. Chen, C. K. Hsu, and H. Y. Hong, "InGaN-CdSe-ZnSe quantum dots white LEDs," IEEE Photonics Technology Letters, vol. 18, no. 1, pp. 193-195, 2006.

[19] E. Jang, S. Jun, H. Jang, J. Lim, B. Kim, and Y. Kim, "White-lightemitting diodes with quantum dot color converters for display backlights," Advanced Materials, vol. 22, no. 28, pp. 3076-3080, 2010. 
[20] M. A. Schreuder, J. D. Gosnell, N. J. Smith, M. R. Warnement, S. M. Weiss, and S. J. Rosenthal, "Encapsulated white-light CdSe nanocrystals as nanophosphors for solid-state lighting," Journal of Materials Chemistry, vol. 18, no. 9, pp. 970-975, 2008.

[21] S. Nizamoglu, T. Erdem, X. W. Sun, and H. V. Demir, "Warmwhite light-emitting diodes integrated with colloidal quantum dots for high luminous efficacy and color rendering," Optics Letters, vol. 35, no. 20, pp. 3372-3374, 2010.

[22] S. Nizamoglu, G. Zengin, and H. V. Demir, "Color-converting combinations of nanocrystal emitters for warm-white light generation with high color rendering index," Applied Physics Letters, vol. 92, no. 3, Article ID 031102, 2008.

[23] C.-Y. Shen, K. Li, Q.-L. Hou, H.-J. Feng, and X.-Y. Dong, "White LED based on YAG : Ce,Gd phosphor and CdSe-ZnS core/shell quantum dots," IEEE Photonics Technology Letters, vol. 22, no. 12, pp. 884-886, 2010.

[24] K. Kim, J. Y. Woo, S. Jeong, and C. S. Han, "Photoenhancement of a quantum dot nanocomposite via UV annealing and its application to white LEDs," Advanced Materials, vol. 23, no. 7, pp. 911-914, 2011.

[25] H. S. Jang, B. Kwon, H. Yang, and D. Y. Jeon, "Bright three-band white light generated from $\mathrm{CdSe} / \mathrm{ZnSe}$ quantum dot-assisted $\mathrm{Sr}_{3} \mathrm{SiO}_{5}: \mathrm{Ce}^{3+}, \mathrm{Li}^{+}$-based white light-emitting diode with high color rendering index," Applied Physics Letters, vol. 95, no. 16, Article ID 161901, 2009.

[26] X. Wang, X. Yan, W. Li, and K. Sun, "Doped quantum dots for white-light-emitting diodes without reabsorption of multiphase phosphors," Advanced Materials, vol. 24, no. 20, pp. 2742-2747, 2012.

[27] S. L. Castro, S. G. Bailey, R. P. Raffaelle, K. K. Banger, and A. F. Hepp, "Synthesis and characterization of colloidal $\mathrm{CuInS}_{2}$ nanoparticles from a molecular single-source precursor," Journal of Physical Chemistry B, vol. 108, no. 33, pp. 12429-12435, 2004.

[28] L. Li, T. J. Daou, I. Texier, T. T. K. Chi, N. Q. Liem, and P. Reiss, "Highly luminescent $\mathrm{CuInS}_{2} / \mathrm{ZnS}$ Core/Shell Nanocrystals: cadmium-free quantum dots for in vivo imaging," Chemistry of Materials, vol. 21, no. 12, pp. 2422-2429, 2009.

[29] H. Zhong, S. S. Lo, T. Mirkovic et al., "Noninjection gram-scale synthesis of monodisperse pyramidal CuInS $\mathrm{S}_{2}$ nanocrystals and their size-dependent properties," ACS Nano, vol. 4, no. 9, pp. 5253-5262, 2010.

[30] W. Liu, Y. Zhang, J. Zhao et al., "Photoluminescence of indiumrich copper indium sulfide quantum dots," Journal of Luminescence, vol. 162, pp. 191-196, 2015.

[31] H. Nakamura, W. Kato, M. Uehara et al., "Tunable photoluminescence wavelength of chalcopyrite $\mathrm{CuInS}_{2}$-based semiconductor nanocrystals synthesized in a colloidal system," Chemistry of Materials, vol. 18, no. 14, pp. 3330-3335, 2006.

[32] J. Zhang, R. Xie, and W. Yang, "A simple route for highly luminescent quaternary $\mathrm{Cu}-\mathrm{Zn}$-In-S nanocrystal emitters," Chemistry of Materials, vol. 23, no. 14, pp. 3357-3361, 2011.

[33] J. Feng, M. Sun, F. Yang, and X. Yang, "A facile approach to synthesize high-quality $\mathrm{Zn}_{x} \mathrm{Cu}_{y} \mathrm{InS1.5}+X_{+0.5 Y}$ nanocrystal emitters," Chemical Communications, vol. 47, no. 22, pp. 64226424, 2011.

[34] W. Chung, H. Jung, C. H. Lee, S. H. Park, J. Kim, and S. H. $\mathrm{Kim}$, "Synthesis and application of non-toxic $\mathrm{ZnCuInS}_{2} / \mathrm{ZnS}$ nanocrystals for white LED by hybridization with conjugated polymer," Journal of the Electrochemical Society, vol. 158, no. 12, pp. H1218-H1220, 2011.
[35] W.-S. Song and H. Yang, "Efficient white-light-emitting diodes fabricated from highly fluorescent copper indium sulfide core/shell quantum dots," Chemistry of Materials, vol. 24, no. 10, pp. 1961-1967, 2012.

[36] B. Chen, Q. Zhou, J. Li et al., "Red emissive $\mathrm{CuInS}_{2}$-based nanocrystals: a potential phosphor for warm white lightemitting diodes," Optics Express, vol. 21, no. 8, pp. 10105-10110, 2013.

[37] W. Liu, Y. Zhang, W. Zhai et al., “Temperature-dependent photoluminescence of $\mathrm{ZnCuInS/ZnSe/ZnS} \mathrm{quantum} \mathrm{dots,"} \mathrm{Journal}$ of Physical Chemistry C, vol. 117, no. 38, pp. 19288-19294, 2013.

[38] P. Gu, Y. Zhang, Y. Feng et al., "Real-time and on-chip surface temperature sensing of GaN LED chips using PbSe quantum dots," Nanoscale, vol. 5, no. 21, pp. 10481-10486, 2013.

[39] X. Zhang, Y. Zhang, L. Yan et al., "High photocurrent PbSe solar cells with thin active layers," Journal of Materials Chemistry A, vol. 3, no. 16, pp. 8501-8507, 2015.

[40] Y. Zhang, Q. Dai, X. Li, B. Zou, Y. Wang, and W. W. Yu, "Beneficial effect of tributylphosphine to the photoluminescence of PbSe and PbSe/CdSe nanocrystals," Journal of Nanoparticle Research, vol. 13, no. 9, pp. 3721-3729, 2011.

[41] Y. Zhang, Q. Dai, X. Li et al., "PbSe/CdSe and PbSe/CdSe/ZnSe hierarchical nanocrystals and their photoluminescence," Langmuir, vol. 27, no. 15, pp. 9583-9587, 2011.

[42] S. A. Crooker, J. A. Hollingsworth, S. Tretiak, and V. I. Klimov, "Spectrally resolved dynamics of energy transfer in quantumdot assemblies: towards engineered energy flows in artificial materials," Physical Review Letters, vol. 89, no. 18, Article ID 186802, 2002.

[43] S. F. Wuister, I. Swart, F. van Driel, S. G. Hickey, and C. de Mello Donegá, "Highly luminescent water-soluble CdTe quantum dots," Nano Letters, vol. 3, no. 4, pp. 504-507, 2003.

[44] H. Kim, B.-H. Kwon, M. Suh, D. S. Kang, Y. Kim, and D. Y. Jeon, "Degradation characteristics of red light-emitting CuInS2/ZnS quantum dots as a wavelength converter for LEDs," Electrochemical and Solid-State Letters, vol. 14, no. 10, pp. K55K57, 2011.

[45] S. R. Forrest, D. D. C. Bradley, and M. E. Thompson, "Measuring the efficiency of organic light-emitting devices," Advanced Materials, vol. 15, no. 13, pp. 1043-1048, 2003.

[46] B. S. Mashford, M. Stevenson, Z. Popovic et al., "High-efficiency quantum-dot light-emitting devices with enhanced charge injection," Nature Photonics, vol. 7, no. 5, pp. 407-412, 2013.

[47] J. Piprek, "Unified model for the GaN LED efficiency droop," in Gallium Nitride Materials and Devices VI, 793916, vol. 7939 of Proceedings of SPIE, March 2011.

[48] H. Zhao, G. Liu, J. Zhang, R. A. Arif, and N. Tansu, "Analysis of internal quantum efficiency and current injection efficiency in III-nitride light-emitting diodes," Journal of Display Technology, vol. 9, no. 4, pp. 212-225, 2013.

[49] K.-J. Chen, H.-C. Chen, M.-H. Shih et al., "The influence of the thermal effect on CdSe/ZnS quantum dots in light-emitting diodes," Journal of Lightwave Technology, vol. 30, no. 14, Article ID 6186747, pp. 2256-2261, 2012.

[50] S. Bhushan and M. V. Chukichev, "Temperature dependent studies of cathodoluminescence of green band of $\mathrm{ZnO}$ crystals," Journal of Materials Science Letters, vol. 7, no. 4, pp. 319-321, 1988.

[51] D. Valerini, A. Cretí, M. Lomascolo, L. Manna, R. Cingolani, and M. Anni, "Temperature dependence of the photoluminescence properties of colloidal CdSeZnS core/shell quantum dots 
embedded in a polystyrene matrix," Physical Review B, vol. 71, no. 23, Article ID 235409, 2005.

[52] G. Morello, M. De Giorgi, S. Kudera, L. Manna, R. Cingolani, and M. Anni, "Temperature and size dependence of nonradiative relaxation and exciton-phonon coupling in colloidal CdTe quantum dots," The Journal of Physical Chemistry C, vol. 111, no. 16, pp. 5846-5849, 2007.

[53] R. Liang, R. Tian, W. Shi et al., "A temperature sensor based on CdTe quantum dots-layered double hydroxide ultrathin films via layer-by-layer assembly," Chemical Communications, vol. 49, no. 10, pp. 967-971, 2013.

[54] V. Biju, Y. Makita, A. Sonoda, H. Yokoyama, Y. Baba, and M. Ishikawa, "Temperature-sensitive photoluminescence of CdSe quantum dot clusters," Journal of Physical Chemistry B, vol. 109, no. 29, pp. 13899-13905, 2005.

[55] W. Liu, Y. Zhang, H. Wu et al., "Planar temperature sensing using heavy-metal-free quantum dots with micrometer resolution," Nanotechnology, vol. 25, no. 28, Article ID 285501, 2014.

[56] S. Li, K. Zhang, J.-M. Yang, L. Lin, and H. Yang, "Single quantum dots as local temperature markers," Nano Letters, vol. 7, no. 10, pp. 3102-3105, 2007.

[57] A. Shi, X. Wang, X. Meng, X. Liu, H. Li, and J. Zhao, "Temperature-dependent photoluminescence of $\mathrm{CuInS}_{2}$ quantum dots," Journal of Luminescence, vol. 132, no. 7, pp. 1819-1823, 2012.

[58] K. Nose, N. Fujita, T. Omata et al., "Photoluminescence of $\mathrm{CuInS}_{2}$-based semiconductor quantum dots; its origin and the effect of ZnS coating," Journal of Physics: Conference Series, vol. 165, Article ID 012028, 2009. 

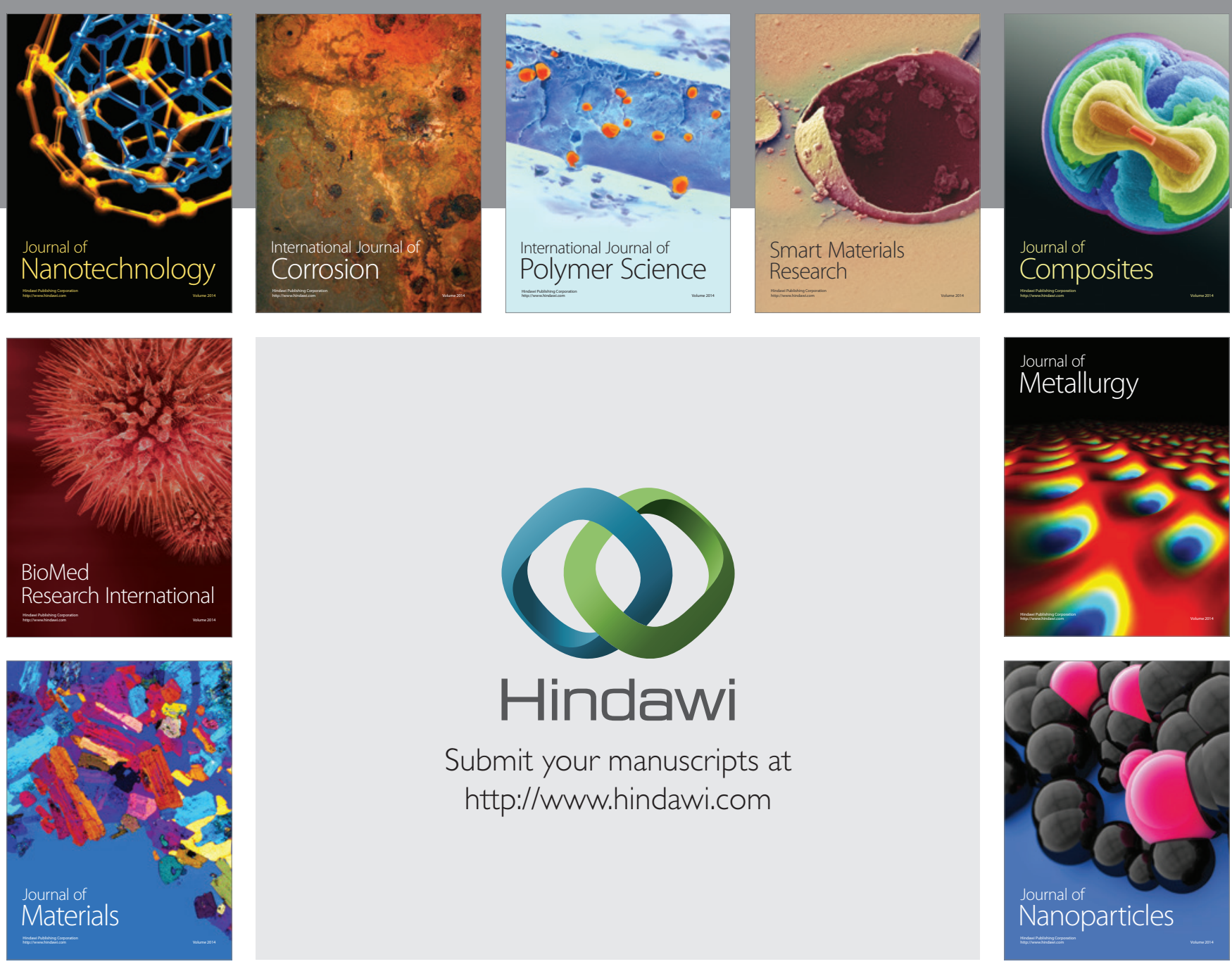

Submit your manuscripts at http://www.hindawi.com
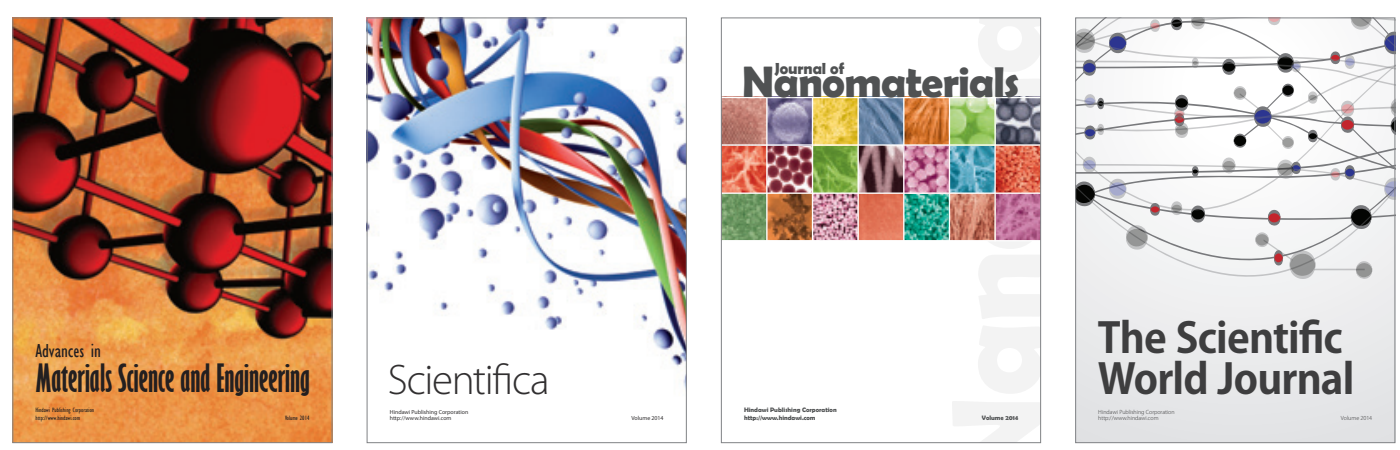

\section{The Scientific World Journal}
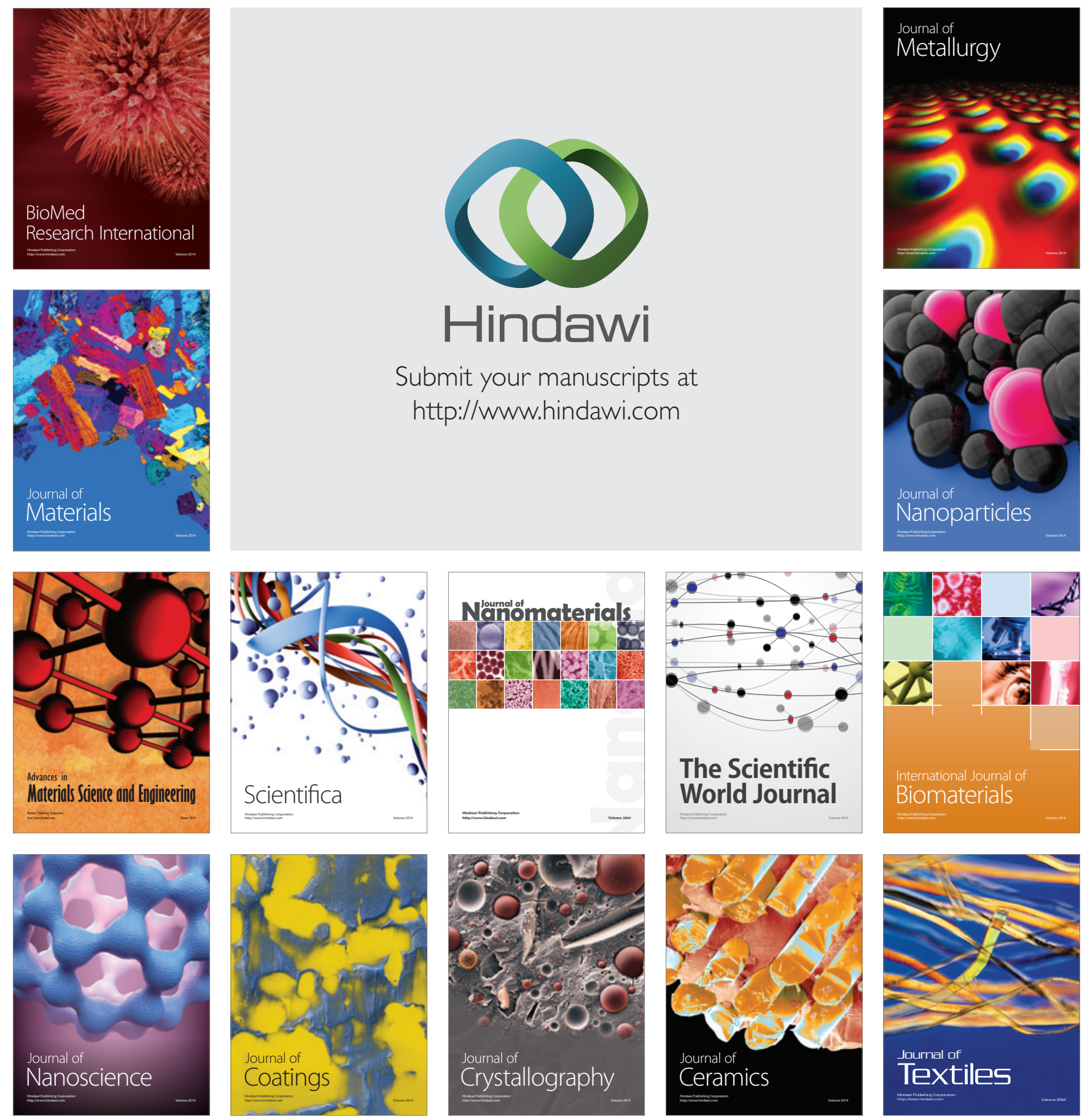